\title{
Stabilization of Angiotensin-(1-7) in Cardioprotective Solutions
}

\author{
Miriam Russ ${ }^{1} \cdot$ Susanne Jauk ${ }^{1} \cdot$ Reinhold Wintersteiger ${ }^{1}$ - Bernd Gesslbauer ${ }^{1}$. Joachim Greilberger ${ }^{2}$. \\ Michaela Andrä ${ }^{3}$. Astrid Ortner ${ }^{1}$
}

Accepted: 4 October 2018 / Published online: 12 October 2018

(c) The Author(s) 2018

\begin{abstract}
Angiotensin-(1-7) (Ang 1-7) has been previously studied in combination with an antioxidant containing preparation as a cardioprotective reperfusion solution. In this study a stability improvement of aqueous Ang 1-7 solutions was observed. However, no data was provided on the responsibilities and causes of the noticed stability enhancement. Therefore, the influence of $\mathrm{pH}$ and pharmaceutical additives as well as the effect of the single specific agents present in the antioxidant preparation such as $\alpha$-ketoglutaric acid ( $\alpha$-KG), 5-hydroxymethylfurfural (5-HMF), $N$-acetyl-seleno-L-methionine (NASeLM) and $\mathrm{N}$-acetyl-L-methionine (NALM) on the stability was evaluated. Analyses were performed by an HPLC method with fluorescence detection. Crucial instability was found in a pH range of 5.0-7.5 without addition of the antioxidative mixture. Zetasizing confirmed the presence of microparticles and MS studies showed no degradation products within 25 days. 5-HMF was identified as main component for stability enhancement of Ang 1-7 solution. By adding this substance the stability of the cardioprotective peptide solution can be prolonged and appears as a promising approach for transplant purposes.
\end{abstract}

Keywords 5-Hydroxymethylfurfural $\cdot$ Angiotensin-(1-7) $\cdot$ Peptide stabilization $\cdot$ HPLC $\cdot$ MS $\cdot$ Fluorescence detection

\section{Introduction}

The heptapeptide angiotensin-(1-7) (Ang 1-7) is an important component of the renin-angiotensin-system and shows a wide range of effects on different organs and tissues. It is formed by proteolysis of angiotensin I or angiotensin II with involvement of endo- or carboxy-peptidases such as prolyl-endopeptidase, neutral-endopeptidase neprilysin, prolyl-carboxypeptidase and angiotensin-converting enzyme 2 (Santos et al. 2000). The activities of Ang 1-7 are mediated via the G-protein-coupled Mas-receptor (Santos et al. 2008, 2013). In the cardiovascular system it counteracts the activity of angiotensin II and promotes vasorelaxation through the release of nitric oxide. Besides, Ang

Astrid Ortner

astrid.ortner@uni-graz.at

1 Department of Pharmaceutical Chemistry, Institute of Pharmaceutical Sciences, University of Graz, Schubertstraße 1, 8010 Graz, Austria

2 Institute of Physiological Chemistry, Medical University of Graz, Harrachgasse 21, 8010 Graz, Austria

3 Division of Transplant Surgery, Medical University of Graz, Auenbruggerplatz 29, 8036 Graz, Austria
1-7 exhibits antiproliferative and antiangiogenic effects, contributes to inflammation processes, and also has positive effects on metabolism with respect to glucose uptake, lipolysis and insulin resistance (Santos et al. 2000; Giani et al. 2008; Liu et al. 2012). Ang 1-7 further showed positive effects on reperfusion arrhythmias in studies carried out with the Langendorff method on isolated hearts of male rats (Ferreira et al. 2001; Neves et al. 1997). This peptide has been tested in combination with an antioxidant solution to improve reperfusion injury after heart transplantation. The active ingredients of this solution are $\alpha$-ketoglutaric acid ( $\alpha$-KG), 5-hydroxymethylfurfural (5-HMF), $N$-acetylseleno-L-methionine (NASeLM) and $N$-acetyl-L-methionine (NALM). It also contains glucose and electrolytes like potassium and sodium. Since this combination is supposed to reduce reactive oxygen and nitrogen species and graft failure effect during the ischemic phase of heart transplantations, it is currently being studied in the hearts of male Wistar rats (Schwarz et al. 2012). In the future, this peptide combination may be used as a liquid storage medium or reperfusion solution in transplant surgery.

In order to ensure the quality of clinically applied peptide solutions a further essential aspect, besides the pharmacological studies, is the investigation of the stability of the 
peptide. Considering liquid peptide preparations, a loss of peptide can occur physically (e.g. aggregation, adsorption) or chemically (e.g. oxidation, deamination) (Avanti 2012; Badelin et al. 1990; Anik and Jiin-Yu 1983). Although peptide instability in aqueous solution is generally known, it is affected by the specific structure of the peptide itself ( $\mathrm{Li}$ et al. 2014; Brange and Langkjaer 1992). Hence, the concept of stabilization differs from peptide to peptide and has to be examined.

There are only a few publications that mention the stability of Ang 1-7, but without further details. Cui et al. and Ali et al. recognized a significant decrease in angiopeptide quantity within less than a week. Both used a water/acetonitrile mixture with formic acid as solvent for the Ang 1-7 solution, but without information on storage conditions, $\mathrm{pH}$ value and additives (Cui et al. 2007; Ali et al. 2014). During the development of our HPLC method for determining Ang 1-7 (Russ et al. 2016), a stability enhancement after addition of an antioxidative solution was noticed. However, up to now no information is given on causes of such an enhancement and possibilities for further improvement. Therefore, the aim of this study was to examine the different ingredients and their possible effects in order to explain this unexpected stabilizing behavior. For these investigations HPLC with fluorescence detection, MS and zetasizing were applied. Since this solution might not be used within a short period of time after production, the data presented in this study provide valuable information for the clinical use of this solution as a potential storage medium or reperfusion solution in heart transplant surgery.

\section{Materials and Methods}

\section{Reagents and Materials}

All chemicals and reagents were of analytical grade and were applied without further purification. HPLC grade deionized water was used for all experiments. Ang 1-7 as acetate salt hydrate and benzalkonium chloride were obtained from Sigma-Aldrich (Vienna, Austria). The antioxidant solution and its individual ingredients $\alpha-\mathrm{KG}, 5-\mathrm{HMF}$, glucose, NASeLM and NALM were supplied by CYL-Pharma (Lassnitzhöhe, Austria). Fluorescamine was purchased from Alfa Aesar, sodium hydroxide and potassium hydroxide from Roth (both Karlsruhe, Germany). Disodium hydrogen phosphate, sodium dihydrogen phosphate, acetonitrile, hydrochloric acid and sodium azide were obtained from Merck (Darmstadt, Germany).

\section{Apparatus}

HPLC analysis was carried out with an Agilent Technologies 1260 Infinity Quat Pump VL and a RF-10AXL Shimadzu Fluorescence Detector. Quantification was performed as described elsewhere (Russ et al. 2016). Under these conditions the retention time of Ang 1-7 was about $4.7 \mathrm{~min}$. In the linear range from 50 to $5000 \mathrm{ng} / \mathrm{mL}$ standard deviation was lower than $5 \%$ and accuracy was between -1.99 and $+2.62 \%$. LOD was determined to be $15 \mathrm{ng} / \mathrm{mL}$. The peptide was derivatized by adding an appropriate amount of fluorescamine at room temperature, likewise according to Russ et al. (2016). The reaction mixture was then injected into the HPLC system via a $20 \mu \mathrm{L}$ loop and detected at $390 \mathrm{~nm}$ excitation and $470 \mathrm{~nm}$ emission wavelength. Triplicates were injected and peak areas evaluated using the Agilent ChemStation software. For comparison of different conditions, peak areas were plotted against the day of measurement (time), applying mean values and standard deviation. For accurate determination of stability, a freshly prepared Ang 1-7 standard solution, defined as $100 \%$ peak area, was applied at each time point.

Offline nano-ESI MS analysis of Ang 1-7 was performed with metal-coated borosilicate emitters connected to a LTQ XL mass spectrometer with the Nanospray Flex Ion Source (all Thermo Scientific). Samples were diluted with water to a final concentration of 3 and $20 \mathrm{pmol} / \mu \mathrm{L}$. A spray voltage of $1.5 \mathrm{kV}$ was applied to the emitter and data analysis performed in the profile mode using a heated capillary temperature of $200{ }^{\circ} \mathrm{C}$ and a capillary voltage of $45 \mathrm{~V}$.

The Litesizer 331 running Kalliope software was used for zetasizing (both prototypes from Anton Paar, Austria).

\section{Preparation of Stock and Standard Solutions}

For every measurement series, stock solutions of $20 \mu \mathrm{g} /$ $\mathrm{mL}$ Ang 1-7 dissolved in water or solutions with particular ingredients were prepared and diluted with the appropriate solvent. The final standard solutions contained 5000, 1000 or $100 \mathrm{ng} / \mathrm{mL}$ of Ang 1-7. On the first day of a series, the standard solutions were prepared and an aliquot of about $200 \mu \mathrm{L}$ was transferred to Eppendorf ${ }^{\circledR}$ tubes, one for each measurement day. All tubes were stored refrigerated at $4{ }^{\circ} \mathrm{C}$ overnight.

\section{Stability Experiments}

The ingredients of the aforementioned cardioprotective solution (Schwarz et al. 2012) were studied to identify any possible stabilizing effect on Ang 1-7. To this end, stock and standard Ang 1-7 solutions containing $\alpha-\mathrm{KG}$ (62 mM), 
5-HMF (24 mM), NALM (0.5 mM), NASeLM (0.008 mM), or the pharmaceutical excipient glucose $(166 \mathrm{mM})$, each as a single compound, were prepared with $\mathrm{pH}$ adjustment to 5.7, the final $\mathrm{pH}$ of the cardioprotective solution.

To study the $\mathrm{pH}$ effect, aqueous stock and standard solutions of the heptapeptide were adjusted to $\mathrm{pH} 2,4,7,9$, and 11 with $0.1 \mathrm{M} \mathrm{HCl}$ or $0.1 \mathrm{M} \mathrm{NaOH}$. Aqueous solutions in a closer range between $\mathrm{pH}$ 5.0-7.5 were also prepared this way. Milli-Q-water ( $\mathrm{pH}$ 5.6) was used for stock and standard solutions. A non-aseptic preparation effect was evaluated by applying antibacterial ingredients like a $0.1 \%$ sodium azide or $0.01 \%$ benzalkonium chloride solutions to Ang 1-7 stock and standard samples.

\section{Results and Discussion}

\section{HPLC Analysis}

An HPLC method with fluorescence detection was used to study the stability of Ang 1-7 in aqueous solutions (Russ et al. 2016), while offline nano-ESI MS was also applied to detect possible degradation products with high sensitivity and specificity.

As the concentration of the analyte may also influence stability, three different concentrations of Ang 1-7 solutions
$(5000,1000$ or $100 \mathrm{ng} / \mathrm{mL})$ were stored under varying conditions. The resulting peak areas were plotted against time (1-25 or in the case of $\mathrm{pH}$ dependence up to 90 days). Figure 1A shows typical chromatograms of Ang 1-7 and its rapid decrease within 25 days at $\mathrm{pH} 6$. Figure $1 \mathrm{~B}$ indicates, there is only a small difference between day 1 and day 25 when applying 5-HMF in the aqueous Ang 1-7 solution. As can be seen the additional peaks with retention time between 2.5 and 3.2 min are attributed to 5-HMF and blank.

\section{Effects of Active and Auxiliary Ingredients}

Previous investigations with an antioxidative solution $(\mathrm{pH}$

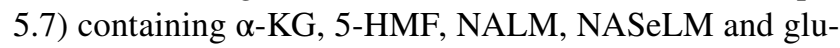
cose showed a positive influence on stability of Ang 1-7 (Russ et al. 2016), but it was unclear which of the compounds was responsible for this protective effect. To clarify this issue, solutions were tested containing the single ingredients $\alpha$-KG (62 mM), 5-HMF (24 mM), NALM $(0.5 \mathrm{mM})$, NASeLM $(0.008 \mathrm{mM})$, and glucose $(166 \mathrm{mM})$ at $\mathrm{pH} 5.7$, each with the same concentration of Ang 1-7. As Fig. 2 shows, the stabilizing effect can be attributed to 5-HMF, which undergoes a loss of only about $10 \%$ within 25 days. The stabilizing behavior of 5-HMF can possibly be attributed to antioxidative ( $\mathrm{Li} 2009$ ) and antibacterial activity (Nafea et al. 2011) of 5-HMF. As the solution was prepared
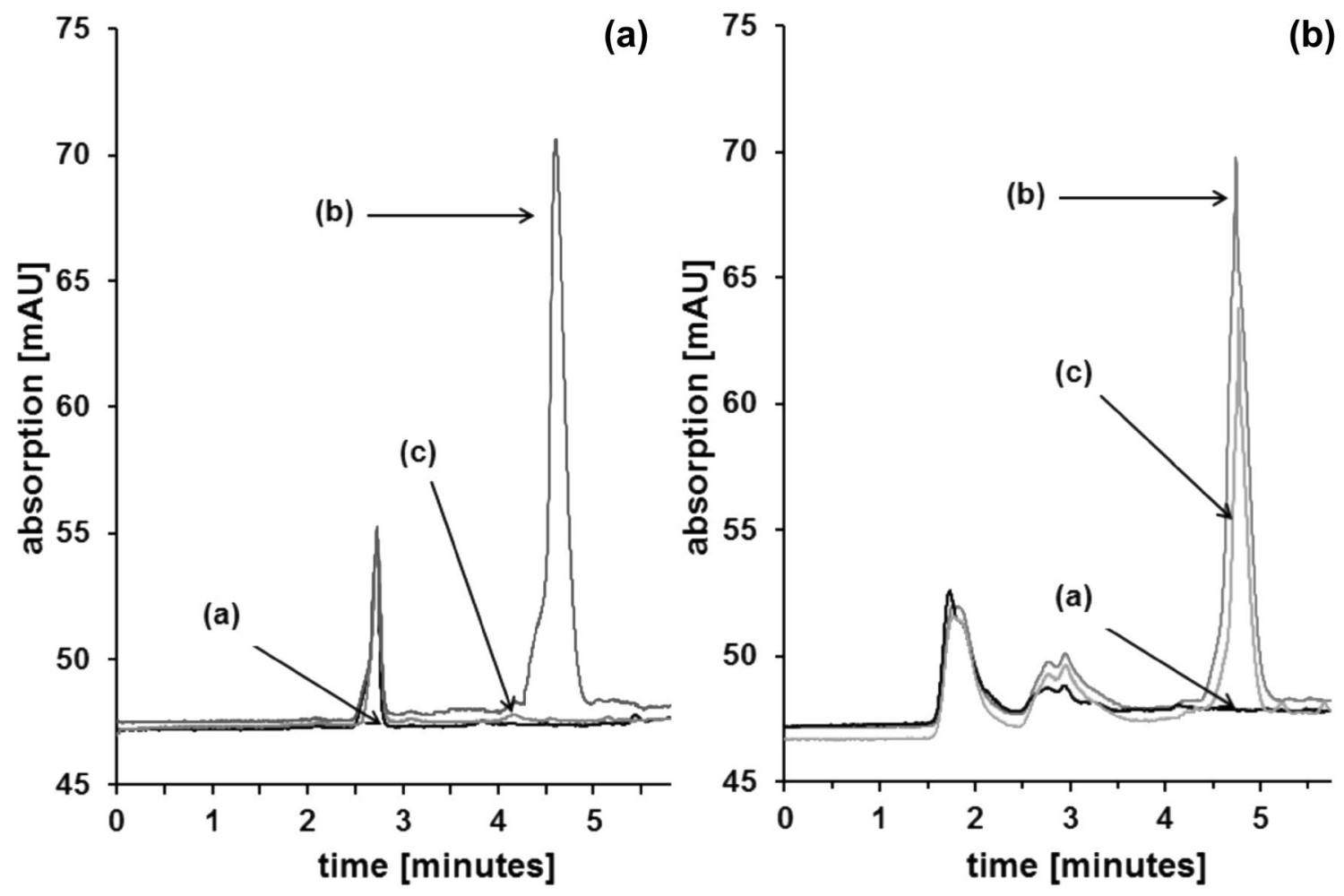

Fig. 1 Time dependent degradation of Ang 1-7 solution without (A) and with (B) 5-HMF: (a) blank, (b) day 1, and (c) day 25 


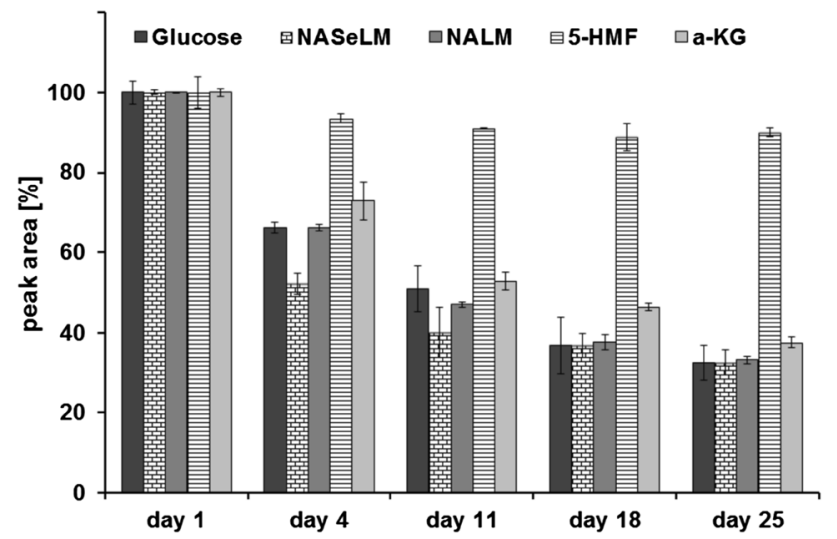

Fig. 2 Influence of single active and auxiliary ingredients on Ang 1-7 stability in solutions with $\mathrm{pH}$ adjustment

under non-aseptic conditions for basic investigations, bacterial peptidases may also be a reason for peak area decrease. In addition, HMF may act due to its several reactive sites as solubilizer for the peptide, although this has never been reported. The influence of different $\mathrm{pH}$ values was tested accordingly to obtain information on the correlation of stability and isoelectric point of Ang 1-7 in solution.

\section{Influence of pH-Value}

There is a distinct influence on the stability of Ang 1-7 only at $\mathrm{pH}$ 7. At $\mathrm{pH} 2,4,9$ and 11, there was no significant degradation of the analyte (Fig. 3). After day 25 at pH 7, the concentration of Ang 1-7 was below the limit of detection which had been determined as $15 \mathrm{ng} / \mathrm{mL}$ (Russ et al. 2016). It is well known that when fluorescent agents are used for derivatization, the quantity of fluorescence yield may be influenced by $\mathrm{pH}$ and polarity of solvent. The peak area corresponding to fluorescence intensity of the Ang 1-7 derivative is, however, only minimally affected by different $\mathrm{pH}$ values, and different concentrations of Ang 1-7 (5000, $1000,100 \mathrm{ng} / \mathrm{mL}$ ) influenced the degradation behavior under different $\mathrm{pH}$ conditions only insignificantly. After 3 months, there was a significant decrease of Ang 1-7 concentrations under all $\mathrm{pH}$ conditions.

Because just small differences in $\mathrm{pH}$ may significantly alter stability, a further study in the relevant range of $\mathrm{pH}$ 5.0-7.5 was carried out at small $\mathrm{pH}$ intervals, with a complete decrease in the peak area in all cases. This may be due to the isoelectric point of the peptide and its correspondingly low solubility, resulting in micro-crystallization and thus reduction of the peak area. Zetasizing was performed to detect any microparticles present. It was found that the solutions exhibited polydispersity, which indicates the formation of microparticles. Higher $(\geq 8)$ or lower $(\leq 4) \mathrm{pH}$ values would better prevent instability, but this is not feasible for physiological reasons.

\section{Effect of Antibacterial Ingredients}

It is often infeasible to prepare a fresh solution every day, but medicinal products that are used over a longer period of time may be prone to enhanced bacterial growth. To overcome this problem, agents with bactericidal and bacteriostatic effects can be added to solutions. Both sodium azide and benzalkonium chloride were chosen to investigate the stability of Ang 1-7. Sodium azide is often used at concentrations of $0.05-0.1 \%$ to protect aqueous solutions. Benzalkonium chloride is applied in pharmaceutical preparations at concentrations of $0.001-0.01 \%$ (Kampf 2013). Therefore, these substances were used at concentrations of $0.1 \%$ sodium azide and $0.01 \%$ benzalkonium chloride. With both compounds there was a lesser decrease in the quantity of Ang
Fig. 3 Stability of Ang 1-7 $(1000 \mathrm{ng} / \mathrm{mL})$ at different $\mathrm{pH}$ values

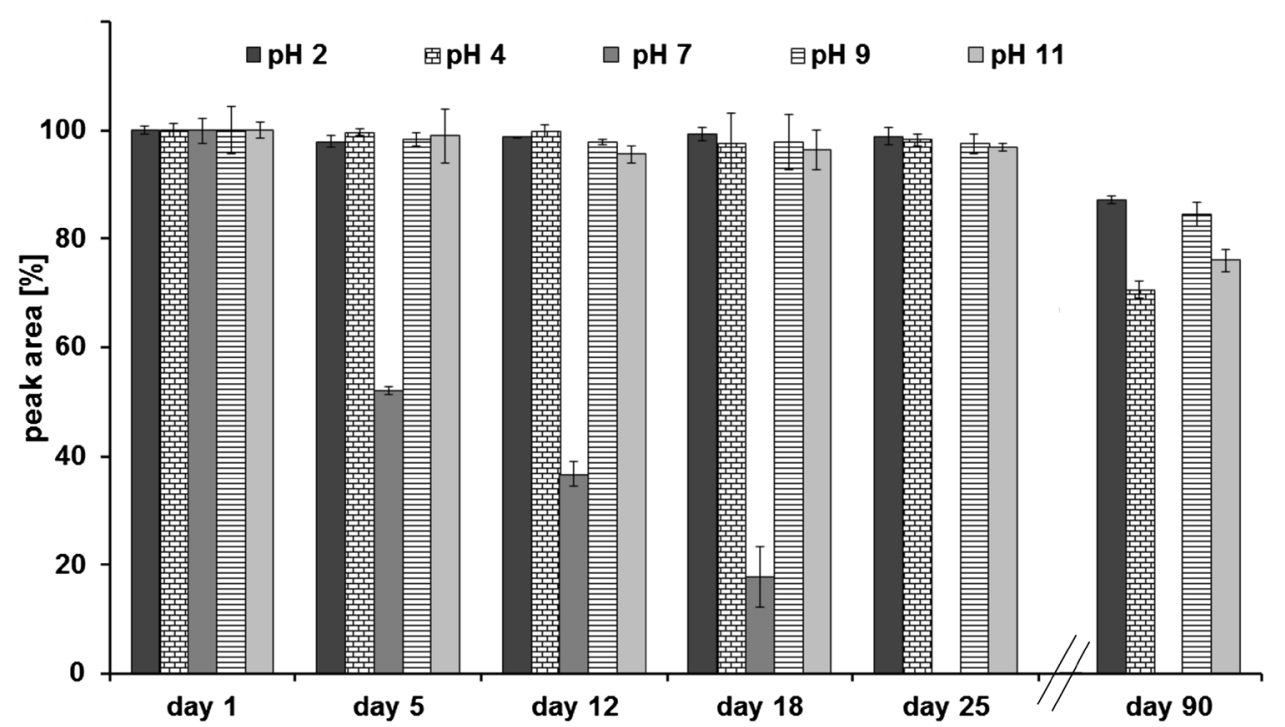




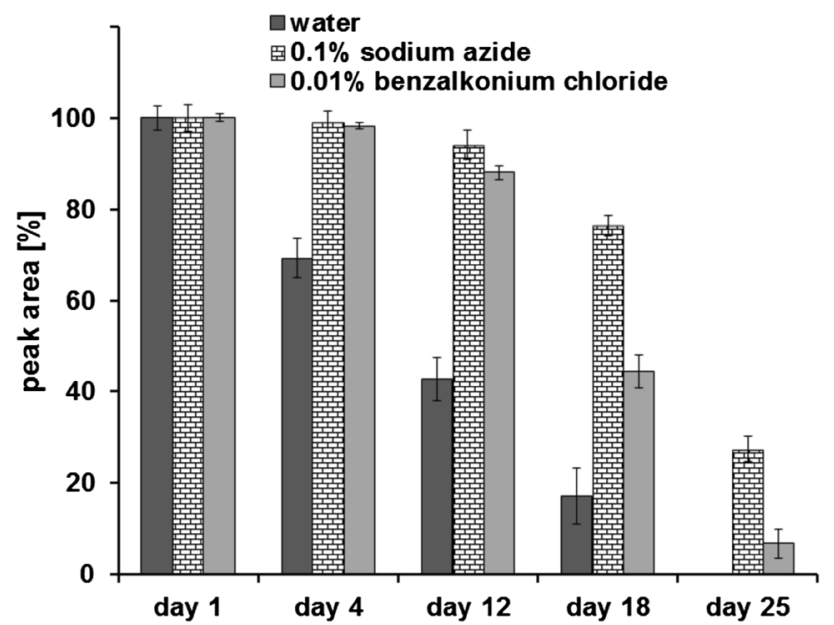

Fig. 4 Effect of antibacterial ingredients on stability of aqueous Ang 1-7 solutions

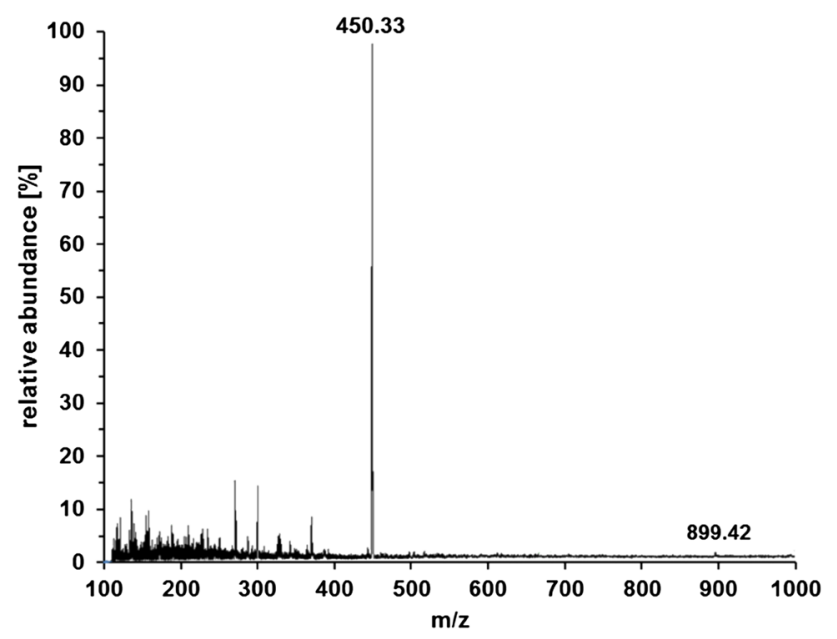

Fig. 5 MS of an aqueous Ang 1-7 solution on day 1

1-7 (Fig. 4) in comparison to aqueous solutions. This effect may be attributed due to inhibition of bacterial growth or to prevented microcrystallization through possible solubilizing properties (Jansook and Loftsson 2009).

\section{MS Investigations}

MS was used to find out more about structural alteration due to a possible bacterial or chemical degradation in aqueous Ang 1-7 solutions. Ang 1-7 is mainly detected as doubly charged ion $\mathrm{m} / \mathrm{z}$ : $450.33\left(\mathrm{M}^{2+}\right)$, along with small quantities of singly charged ions m/z: $899.42\left(\mathrm{M}^{+}\right)$, as shown in Fig. 5.
The concentration of Ang 1-7 decreased by up to $40 \%$ after storage for several weeks at $4{ }^{\circ} \mathrm{C}$, but no degradation products were found. After the solution was intensively vortexed, about $84 \%$ of Ang 1-7 were detected, indicating that most of the microcrystals had re-dissolved (Fig. 6).

An aqueous Ang 1-7 solution that had been stored for 6 months at room temperature was completely degraded. As shown in Fig. 7, storage resulted in the formation of single amino acids and dipeptides, which may be attributed to enzymatic hydrolysis via microorganisms.

\section{Conclusion}

This study investigated the stability of Ang 1-7 in solutions under different conditions. The $\mathrm{pH}$ value in the range of 5.0-7.5 was shown to have considerable influence, decreasing the Ang 1-7 concentration. Higher or lower $\mathrm{pH}$ values, as well as a combination with 5-HMF, significantly prolonged stability. MS studies and zetasizing showed that the decrease in the quantity of Ang 1-7 can be assumed to be due to microcristallization at the relevant $\mathrm{pH}$. Only after several months does microbial degradation to dipeptides and single amino acids take place, as determined by MS analysis.

As the result of this study it can be concluded that 5-HMF shows beside its antibacterial activity (Nafea et al. 2011) also a solubilizing effect on the peptide in aqueous solutions. Basically 5-HMF is able to react with amino acids and form Michael adducts as well as Schiff bases (Nikolov and Yaylayan 2011; Hamzalığlu and Gökmen 2018). Thereby, the aldehyde site of 5-HMF reacts with a primary amine structure of an amino acid. However, a formation of a covalent bond between 5-HMF and Ang 1-7 would lead to an alteration of the retention time during HPLC analysis compared to other Ang 1-7 solutions, which was not observed in this study. Furthermore, the primary amine structure in Ang 1-7, contained in aspartic acid, is also the binding site for the used derivatization dye fluorescamine. If a non-reversible binding of 5-HMF with Ang 1-7 would appear there would be no free binding site for the dye, resulting in a detection of less Ang 1-7, which was again not observed. 5-HMF was identified during this study as stabilizing compound for Ang 1-7, so a non-reversible covalent binding between 5-HMF and the peptide can be excluded. 5-HMF might form reversible hydrogen bridge bonds with Ang 1-7, which increases the polarity of the peptide and leads to this solubilizing effect.

Overall, 5-HMF seems to be a promising approach to improve the stability of Ang 1-7 in aqueous cardioprotective solutions used for organ conservation in transplant surgery without altering its structure and functionality. 

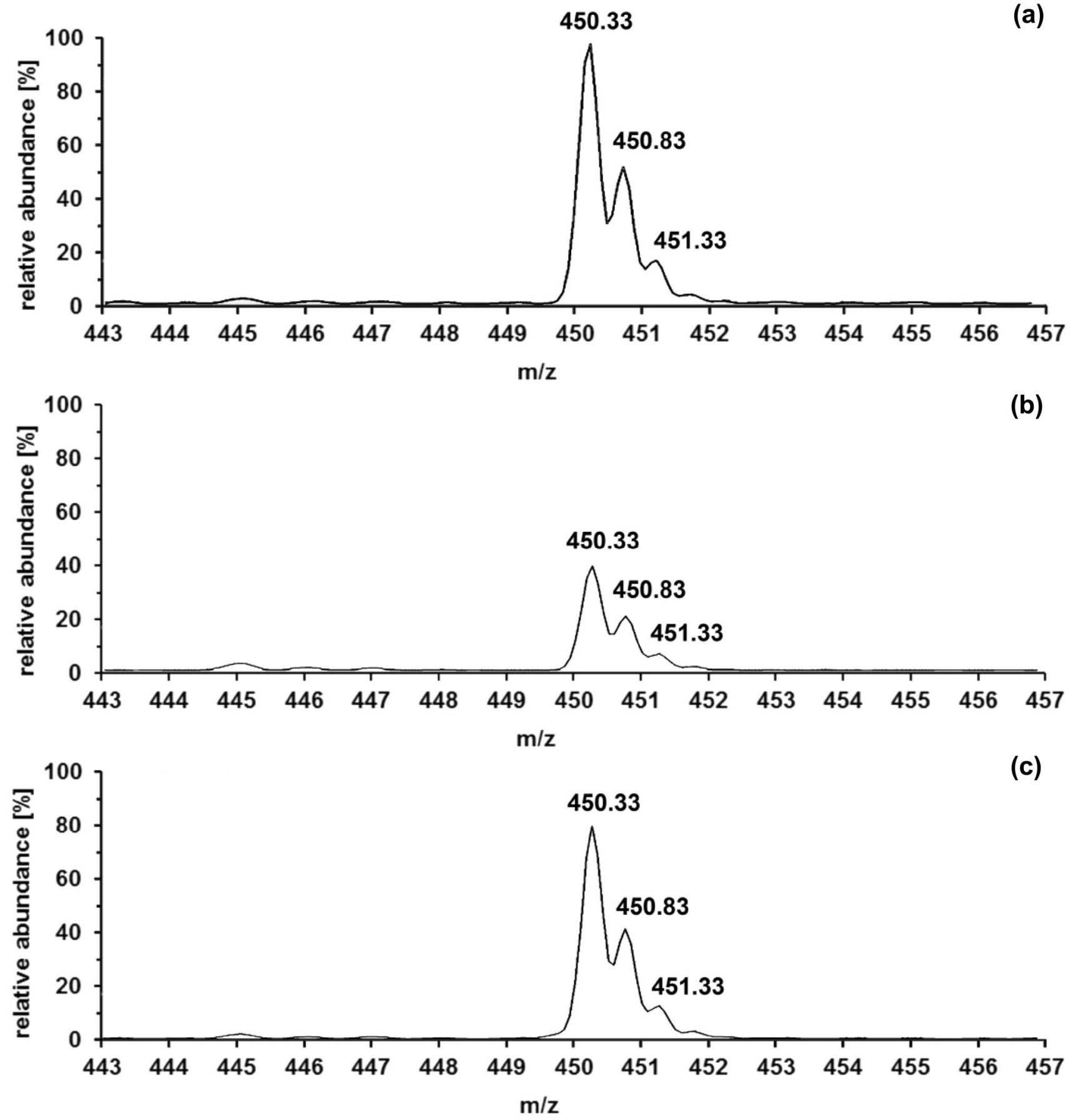

Fig. 6 MS measurement of aqueous Ang 1-7 solutions freshly prepared (a) and after 25 days storage without (b) and with (c) vortexing 
Fig. 7 MS of an aqueous Ang 1-7 solution stored for 6 months at room temperature

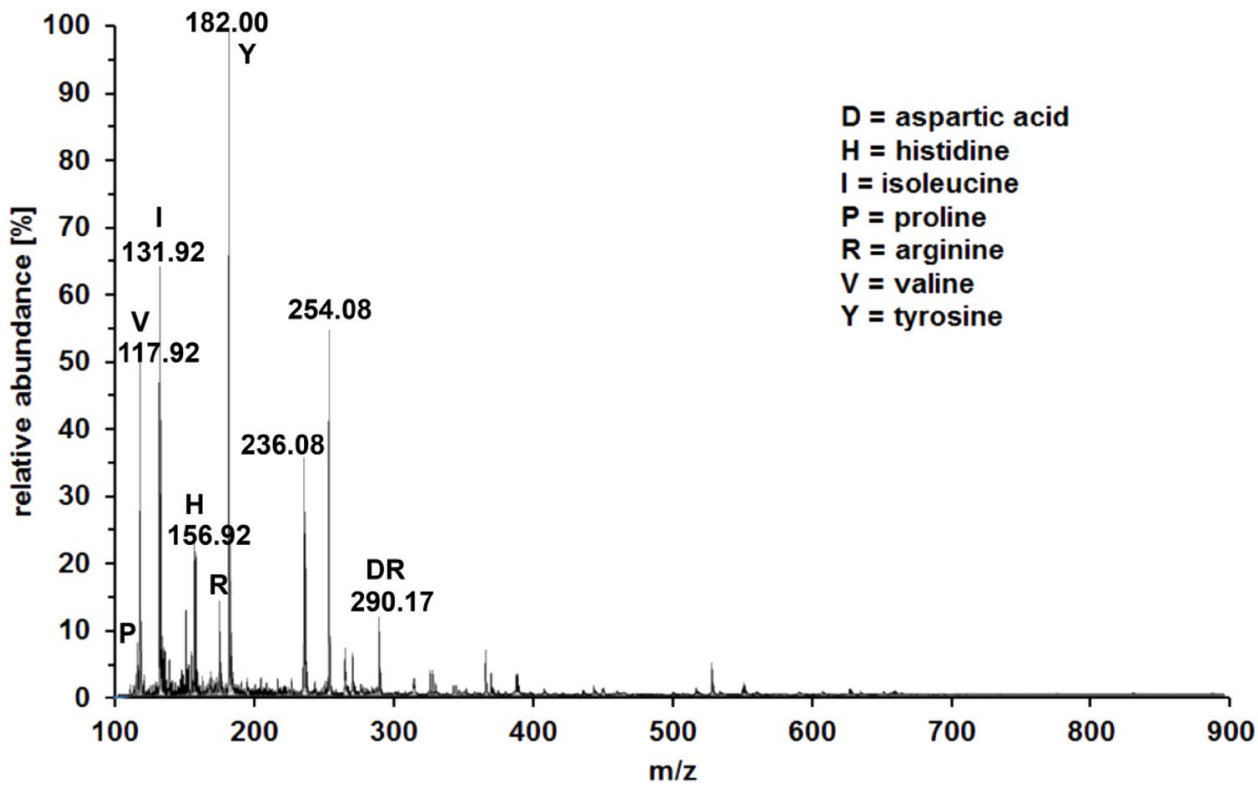

Acknowledgements Open access funding provided by University of Graz.

\section{Compliance with Ethical Standards}

Conflict of Interest The authors declare that they have no conflict of interest.

Open Access This article is distributed under the terms of the Creative Commons Attribution 4.0 International License (http://creativeco mmons.org/licenses/by/4.0/), which permits unrestricted use, distribution, and reproduction in any medium, provided you give appropriate credit to the original author(s) and the source, provide a link to the Creative Commons license, and indicate if changes were made.

\section{References}

Ali Q, Wu Y, Nag S, Hussain T (2014) Estimation of angiotensin peptides in biological samples by LC-MS method. Anal Methods 6:215-222. https://doi.org/10.1039/C3AY41305E

Anik ST, Jiin-Yu H (1983) Adsorption of d-Nal(2) 6LHRH, a decapeptide, onto glass and other surfaces. Int J Pharm 16:181-190. https://doi.org/10.1016/0378-5173(83)90055-8

Avanti C (2012) Innovative strategies for stabilization of therapeutic peptides in aqueous formulations. Dissertation, University of Groningen

Badelin VG, Kulikov OV, Vatagin VS, Udzig E, Zielenkiewicz A, Zielenkiewicz W, Krestov GA (1990) Physico-chemical properties of peptides and their solutions. Thermochim Acta 169:8193. https://doi.org/10.1016/0040-6031(90)80135-L

Brange J, Langkjaer L (1992) Chemical stability of insulin. 3. Influence of excipients, formulation, and $\mathrm{pH}$. Acta Pharm Nord 4:149-158

Cui L, Nithipatikom K, Campbell WB (2007) Simultaneous analysis of angiotensin peptides by LC-MS and LC-MS/MS: metabolism by bovine adrenal endothelial cells. Anal Biochem 369:27-33. https ://doi.org/10.1016/j.ab.2007.06.045
Ferreira AJ, Santos RA, Almeida AP (2001) Angiotensin-(1-7): cardioprotective effect in myocardial ischemia/reperfusion. Hypertension 38:665-668. https://doi.org/10.1161/01.HYP.38.3.665

Giani JF, Mayer MA, Munoz MC, Silberman EA, Hocht C, Taira CA, Gironacci MM, Turyn D, Dominici FP (2008) Chronic infusion of angiotensin-(1-7) improves insulin resistance and hypertension induced by a high-fructose diet in rats. Am J Physiol Endoc M 296:E262-E271. https://doi.org/10.1152/ajpendo.90678.2008

Hamzalı̆̆lu A, Gökmen V (2018) Investigation and kinetic evaluation of the reactions of hydroxymethylfurfural with amino and thiol groups of amino acids. Food Chem 240:354-360. https:// doi.org/10.1016/j.foodchem.2017.07.131

Jansook P, Loftsson T (2009) CDs as solubilizers: Effects of excipients and competing drugs. Int J Pharm 379:32-40. https://doi. org/10.1016/j.ijpharm.2009.06.005

Kampf G (2013) Händehygiene im Gesundheitswesen. Springer, Berlin

Li Y (2009) In vitro antioxidant activity of 5-HMF isolated from marine red alga laurencia undulata in free-radical-mediated oxidative systems. J Microbiol Biotechnol 19:1319-1327. https://doi. org/10.4014/jmb.0901.00004

Li R, Wang F, Chen L, Zhu S, Wu L, Jiang S, Xu Q, Zhu D (2014) Stability of an anti-stroke peptide: driving forces and kinetics in chemical degradation. Int J Pharm 472:148-155. https://doi. org/10.1016/j.ijpharm.2014.06.021

Liu C, Lv X, Li H, Cao X, Zhang F, Wang L, Yu M, Yang J (2012) Angiotensin-(1-7) suppresses oxidative stress and improves glucose uptake via Mas receptor in adipocytes. Acta Diabetol 49:291-299. https://doi.org/10.1007/s00592-011-0348-z

Nafea EA, Moselhy WA, Fawzy AM (2011) Does the HMF value affect the antibacterial activity of the bee honey? Egypt Acad J Biol Sci 4:13-19

Neves LA, Almeida AP, Khosla MC, Campagnole-Santos MJ, Santos RA, Neves L, Khosla MC, Campagnole-Santos MJ, Santos R (1997) Effect of angiotensin-(1-7) on reperfusion arrhythmias in isolated rat hearts. Braz J Med Biol Res 30:801-809. https://doi. org/10.1590/S0100-879X1997000600016

Nikolov PY, Yaylayan VA (2011) Reversible and covalent binding of 5-(hydroxymethyl)-2-furaldehyde (HMF) with lysine and selected amino acids. J Agric Food Chem 59:6099-6107. https://doi. org $/ 10.1021 / \mathrm{jf} 200735 \mathrm{c}$ 
Russ M, Hauser S, Wintersteiger R, Greilberger J, Andrä M, Ortner A (2016) Determination of angiotensin-(1-7) with HPLC/fluorescence-detection. J Fluoresc 26:81-86. https://doi.org/10.1007/ s10895-015-1686-y

Santos RA, Campagnole-Santos MJ, Andrade SP (2000) Angiotensin-(1-7): an update. Regul Pept 91:45-62. https://doi. org/10.1016/S0167-0115(00)00138-5

Santos RA, Ferreira AJ, Simões-e-Silva AC (2008) Recent advances in the angiotensin-converting enzyme 2 -angiotensin(1-7)-Mas axis. Exp Physiol 93:519-527. https://doi.org/10.1113/expph ysiol.2008.042002
Santos RA, Ferreira AJ, Verano-Braga T, Bader M (2013) Angiotensinconverting enzyme 2, angiotensin-(1-7) and Mas: new players of the renin-angiotensin system. J Endocrinol 216:R1-R17. https:// doi.org/10.1530/JOE-12-0341

Schwarz M, Greilberger JF, Lamacie MM, Wasler A, Wintersteiger R, Lang I, Santos RA (2012) 114 Alpha-ketoglutarate, 5-hydroxymethylfurfurale and angiotensin 1-7: cardioprotective effects during myocardial ischemia/reperfusion. Can J Cardiol 28:132. https ://doi.org/10.1016/j.cjca.2012.07.123 